\title{
Constructing A Multi-Microgrid with the Inclusion of Renewable Energy in Oman's Rural Power System
}

\author{
N. Hosseinzadeh*, A. Al Shereiqi, M. Al Badi, and A. Al Hinai \\ Department of Electrical and Computer Engineering, College of Engineering, Sultan Qaboos University, PO Box 33, PC \\ 123, Muscat - Al-Khoud, Oman
}

Received 27 January 2017; Accepted 13 April 2017

\begin{abstract}
This paper investigates the possibility of constructing multi-microgrids by interlinking the rural area systems in the Al Wusta governorate of the Sultanate of Oman, which are currently being supplied by diesel generators. It is proposed to enhance the rural system under study by switching off small diesel stations and replacing them with wind turbines. The microgrids formed in this way are then interlinked together to create multi-microgrids. The paper studies the interlinked multimicrogrids under different scenarios; in terms of voltage profiles and power flow using the ETAP software package. This study contributes to the feasibility study of retiring some diesel power plants and using renewable energy resources in rural Oman.
\end{abstract}

Keywords: Microgrids; Distributed generation; Renewable energy; Distributed energy resources; Multi-microgrids; Rural electricity; Oman.

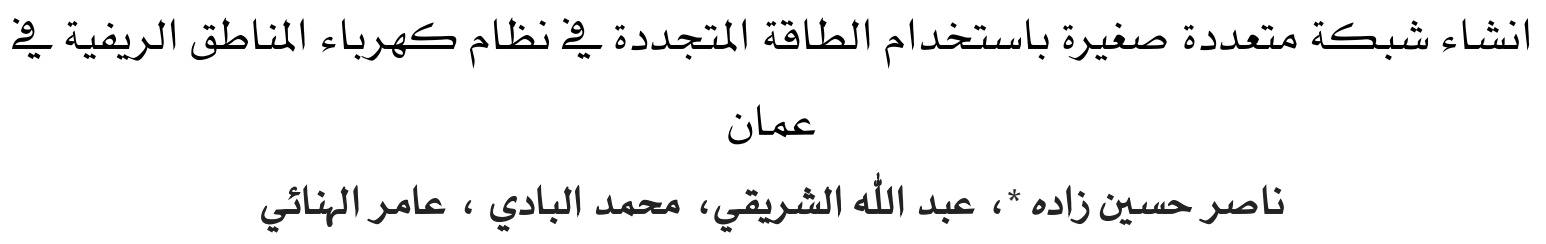

* Corresponding author's e-mail: hosseinz@squ.edu.om 


\section{Introduction}

In any society, an adequate supply of energy is required for the process of modernization, increase in productivity and improvement of standards of living. Electrical energy is used more than other forms of energy because it is clean and easier to transport. Therefore, both the design and construction of electrical system have to be done professionally and according to international standards. Supplying electricity to rural areas, particularly in countries where a small population is dispersed within a large area, is considered to be a challenge. It is argued that extension of the main grid to cover all rural areas is usually a very expensive option compared to other solutions (Mahapatra and Dasappa 2012). In most cases, microgrids (Marnay and Venkataramanan 2006) in either stand-alone mode (Kobayakawa and Kandpal 2016) or, if possible, in a gridconnected mode are a more viable option. Other forms of cost-effective extension of power grids to rural areas have been proposed in the literature (Hosseinzadeh et al. 2011), but with recent advances in electrical generation using renewable energy resources, it appears that developing microgrids in rural areas is a very promising solution for electrification of remote communities from the main power grid. Renewable resources especially solar and wind energy are recommended for use in Oman according to the previous research reports. It has been reported that many studies have indicated that Oman could benefit from its rich solar and wind energy resources (Al Hatmi and Tan 2013).

Microgrids for different applications with different levels of control were developed around the globe. Many types of microgrids with power management capabilities or various control systems have been introduced in the literature, such as (Khodayar et al. 2012; Sun et al. 2015; Chuang et al. 2016; Li et al. 2016; Meng et al. 2016; Mohan et al. 2016).

In this paper, a proposal will be presented to modify the electricity supply of three small towns in the rural area of Oman's electricity network, namely, Hijj, Najdah and Khaloof in the Al Wusta governorate in the Sultanate of Oman. Electric power is currently supplied separately to these three towns using diesel generators. As diesel generators have high operating costs and contribute to environmental pollution, it is aimed to reduce their usage by retiring the small diesel generators, adding renewable energy resources, and interlinking the three electricity networks.

\section{Microgrid}

Generally, any typical power network consists of power generation, transmission and distribution. Naturally, various energy resources, such as diesel, gas, wind and solar, could be used for generating electrical power. Investing in these resources could be done by adopting the concept of microgrid to develop the electricity system. A microgrid (Hatziargyriou, Asano et al. 2007) is a small system which can generate and distribute electrical power to local consumers and can also be connected to a grid. Therefore, it can work in grid-connected mode or islanded mode. The latter mode may be used in failure occurrences in the main grid. In the absence of a grid in the area, the microgrid may be designed to operate completely off-grid.

Microgrids in power systems have been in use for a long time, but recently they are drawing more attention due to expansion of renewable energy resources (Hemmatpour, Mohammadian et al. 2016; Xu, Nthontho et al. 2016). The lack of sufficient resources to balance out the rapid increase in demand and the availability of local generators in the form of renewable-energy power plants have made it possible for electricity utilities to use microgrids for supporting the main grid. Microgrids may use distributed generators (DG) from different resources. One essential requirement will be controlling and coordinating these DGs by taking into consideration the technical and economic aspects of microgrid operation (Esmaeli 2016; Khederzadeh et al. 2016; Moradi et al. 2016; Nikmehr and Ravadanegh 2016). A multi-microgrid is formed by connecting some adjacent microgrids (Schwaegerl and Tao 2014). In this paper, the first phase of forming a multimicrogrid by connecting the microgrids of Hijj, Najdah, and Khaloof is proposed.

A microgrid represents energy distribution architecture from distributed generators to the customer and the interconnection between these sources and the main grid while they offer considerable control capabilities over the network operation (Costa, Matos et al. 2008; Jiayi, Chuanwen et al. 2008; Shahnia 2011). A simple microgrid structure, which is suitable for Oman rural areas, is shown in Fig. 1. For the 
case under study, three such microgrids linked together are proposed. However, in this study, storage units are not included and renewable resources are limited to wind-energy systems. Furthermore, the system is currently not connected to the utility grid.

The dashed rectangle in Fig. 1 shows that the microgrid should be a single controllable entity. Controllers in a microgrid are required to keep functioning in required operational modes (Lasseter 2011). A microgrid, which is connected to the main grid acts like a plug that can easily isolate itself during any abnormality or interruption in the main grid and can continue supplying the load in islanded mode. In gridconnected mode, the microgrid is connected to the main grid via a switch at the point of common coupling (PCC) as shown in Fig. 1.

Rural areas in Oman are far away from the main interconnected system (MIS). Diesel generators are currently used in most of these areas. Accordingly, an increase in the demand could lead to a huge cost increase in operation and maintenance of the small scattered power stations. Additionally, some of the power stations are old, costly to operate and have poor power efficiency. Interlinking the small power stations, leaving bigger ones and retiring small power stations are some of the suggested solutions, which aim to reduce maintenance costs, improve system reliability, reduce operational costs, increase efficiency, and also to reduce reliance on government subsidies.
For retiring some diesel generators, renewable resources are considered as auxiliary supporters to the rural power generation. It is well known that most of the rural areas in Oman have ample wind and solar resources. In the case of this study, a combination of the existing diesel power stations with wind turbines for constructing a microgrid could be one of the best solutions to reduce the use of diesel generators while keeping proper voltage profiles in the power system under study.

It is important to mention that different variable-speed generators may be used in the wind turbines, e.g. squirrel cage induction generators (SCIG), synchronous generators (SG), permanent magnet synchronous generators (PMSG) and doubly fed induction generators (DFIG). The DFIG technology is mostly used in modern wind turbines since it allows a variable-speed operation over a large range. It contains a wind rotor connected to the grid through a converter and stator circuit which is directly connected to the grid. Another advantage of the DFIG technology is the ability of power electronic converters to generate or absorb reactive power, thus controlling the power factor (Senthilkumar and Narmadhadevi 2013).

The expected outcome from this study is that a multi-microgrid will make a major contribution to increase systems efficiency and reliability especially by deploying renewable energy systems.

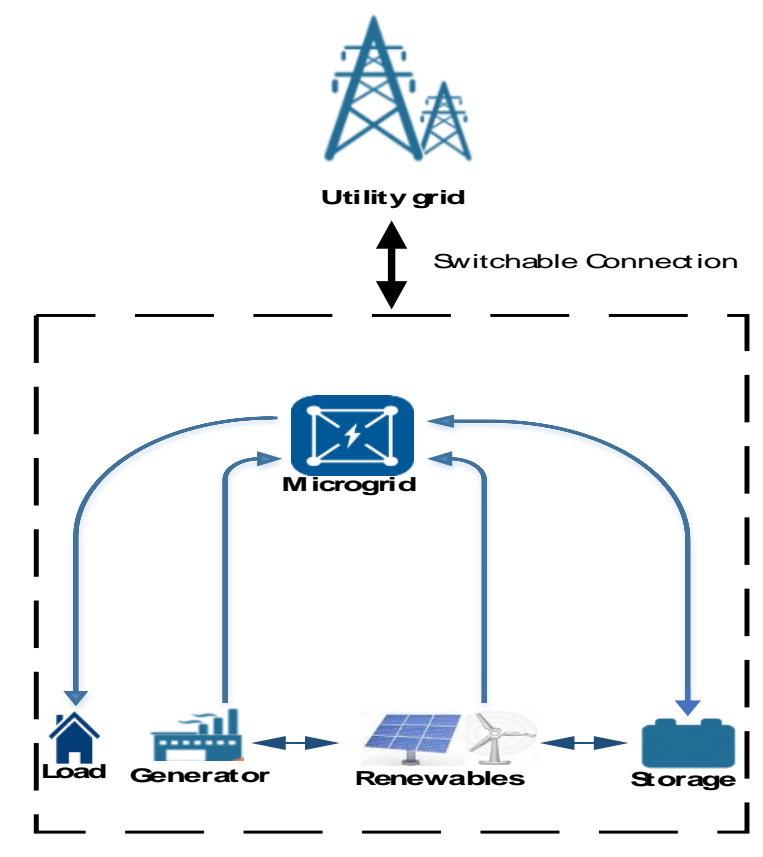

Figure 1. A microgrid structure suitable for rural areas of Oman. 


\section{Case Study}

This case study is based on modelling diesel and wind resources using ETAP software in order to study the impact of this hybrid system on the power flow in an existing network and to explore the possibility of constructing multimicrogrid. The case study is divided into two parts, the first part is about running the system with diesel generators only and the second one introduces wind turbines diesel generators.

\subsection{Part I: Interlinking Systems Using Diesel Generators Only}

In this part, the focus will be on studying the possibility of switching off diesel generators in the smaller villages of Khaloof and Najdah, and interlinking the three systems using bigger diesel generators in Hijj station only. The original system consists of three isolated microgrids with diesel generators in Hijj, Khaloof, and Najdah (see Fig. 2).

The first study suggests interlinking Khaloof and Najdah to Hijj by switching off the smaller diesel generators in Khaloof and Najdah, and adding the dotted lines F1-K and F1-N with the associate step-up and step-down transformers as in Fig. 3.

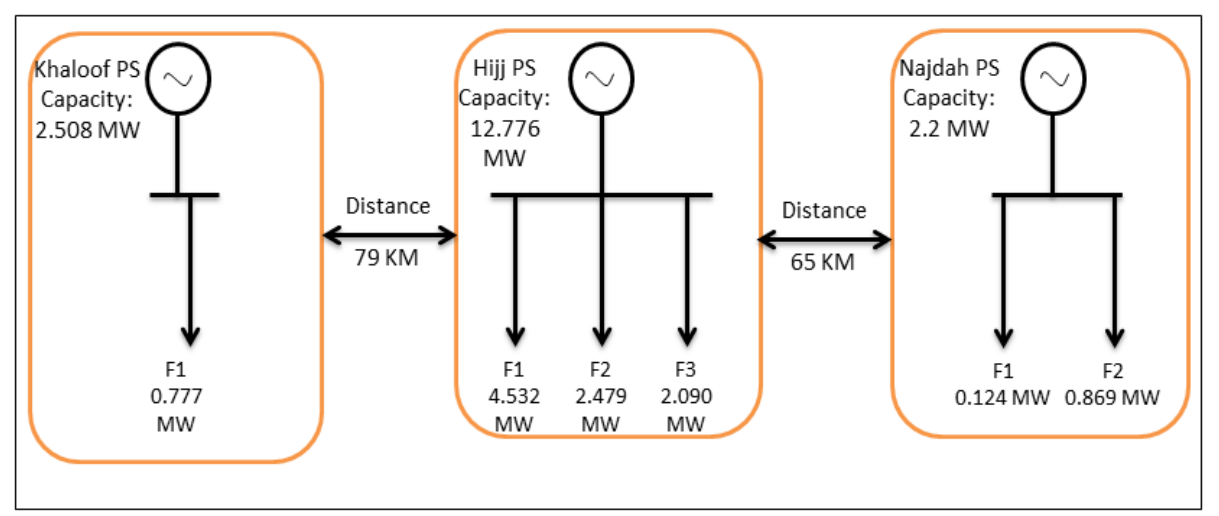

Figure 2. Existing systems in Khaloof, Hijj and Najdah.

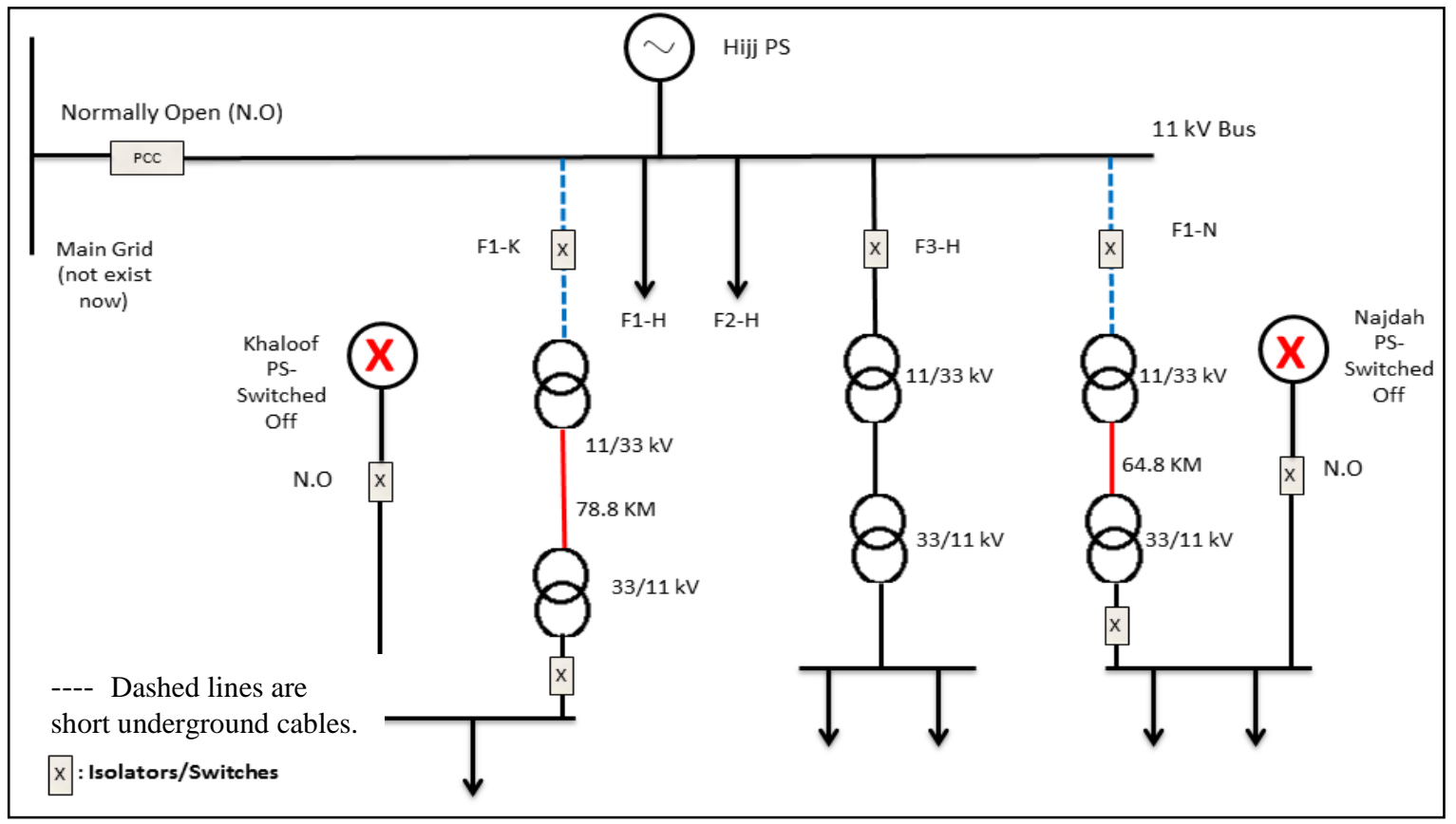

Figure 3. Full scheme for the proposed microgrid. 
The dashed lines in the figure represent the short cables of about $200 \mathrm{~m}$ in length used inside the power station from bus-bar to the step-up transformers. The idea behind this interlinking is to minimize operational cost and to reduce the number of low-efficient power plants. Hijj plant is the main power station in this proposal, whereas Najdah and Khaloof power plants are kept on standby to be used as and whenever needed. One important objective that should be considered in constructing power stations is fuel efficiency. In 2013, fuel consumption in liter/kwh in 2013 was 3.54, 3.0 and 3.0 for Hijj, Khaloof and Najdah power stations, respectively. The retired diesel generators can be used as backup power supplies during power interruption and can also be used during maintenance work in the main power station. It is worth mentioning here that the Rural Area Electricity Company (RAEC) system is not currently connected to the main grid. Thus, the PCC in Fig. 2 is in the open state, i.e. the microgrid is operated in stand-alone (or offgrid) mode. In the future, the RAEC system may get interconnected with the MIS. Additionally, the distributed generators inside the microgrid are supposed to control opening and closing of the switches according to the circumstances and needs of the supply. However, this is beyond the scope of this paper. Controllers are needed for dispatching and regulating load among the DGs. However, at present, there is no SCADA system in the existing network. So, for the time being, the supply can be controlled manually by the system operators.

\subsection{Part II: Interlinking Systems Using Hybrid Wind-Diesel Resources}

This case study is a proposal for combined use of wind and diesel energy to determine whether wind energy can help reduce usage of diesel generators while providing enough energy for demand at all times. This combination will be helpful to minimize the use of diesel generators in the seasons and times when there is sufficient wind speed, which should improve voltage profile at the same time of reducing the use of diesel generators.

In the present scenario, stand-alone diesel generators in Hijj power station feed the load. Due to the drawbacks of diesel generators and advantage of wind energy, it is proposed that wind turbines be used in the same location of the switched off stations which are Najdah and Khaloof. This reduces the operational and maintenance cost of the existing diesel generators in Hijj power station and enhances the advantages of using renewable resources in rural area systems. Although developing a methodology to design and implement hybrid Wind-Diesel microgrid could be very useful, the main objective of this paper is to do a feasibility study of a multi-microgrid from a system point of view. Therefore, the rated power of wind turbines chosen here are simply selected to be close to the rate of the existing diesel generators in Khaloof and Najdah power stations. The wind turbines are connected to the first bus of Khaloof system and the first bus of Najdah system with a rated power of $2.5 \mathrm{MW}$ each to replace the switched off diesel station.

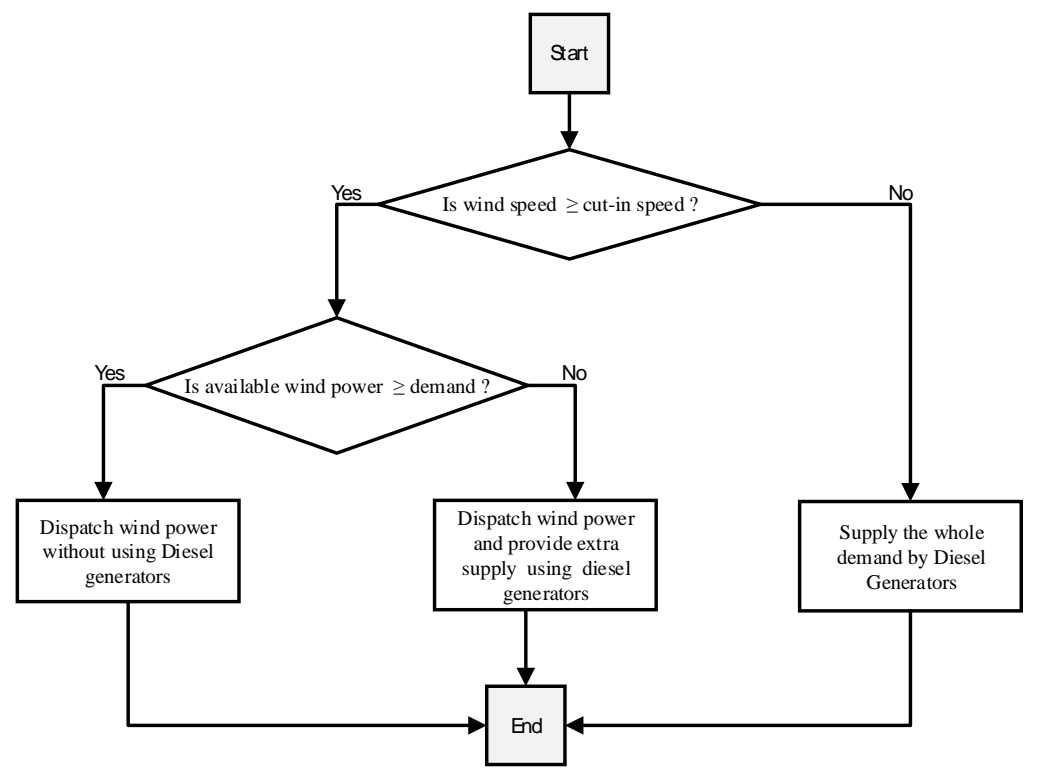

Figure 4. Flow chart of the process of supplying load by the micro-grid. 
The process of supplying the load using both diesel and wind resources is summarized in the diagram of Fig. 4. In this flowchart, it is assumed that some storage units are available to store extra energy produced by wind turbines when wind speed is high and demand is low.

The study in this paper is mainly carried out using power flow analysis. The parameters of wind energy system affecting the power flow are presented in Table 1. Identical parameters are used for Khaloof and Najdah.

The factors affecting wind turbine electricity production are: wind speed (v), air density $(\rho)$ and area swept by the rotor blades (A). The power available in the wind could be described by Eq. (1) whereas the output power from the turbines is described by Eq. (2), where $C_{p}$ is the power coefficient.

$P_{\text {wind }}=0.5\left(\rho A v^{3}\right)$

$\mathrm{P}_{\text {out }}=\mathrm{C}_{\mathrm{p}}\left(\mathrm{P}_{\text {wind }}\right)$

Wind systems were assumed to work at their full capacity, according to the available data for Najdah and Khaloof stations or nearby sites. In this case, the available data for Joba, a nearby village, was used since it is the closest weather station to Najdah and Khaloof. The air density $\rho$ $=1.175 \mathrm{~kg} / \mathrm{m}^{3}$ is used, taken from (Senthilkumar and Narmadhadevi 2013), and the average wind speed is $5.2 \mathrm{~m} / \mathrm{s}$ according to the output of the study carried out by Oman Authority for Electricity Regulation.

The turbine page of the ETAP software shown in Fig. 5 is used to define the characteristics of the turbine by entering the required data manually and representing the power curves automatically. The air density value in the sea level is usually adjusted to 1.225 $\mathrm{kg} / \mathrm{m} 3$, but it is calculated as a function of air pressure and air temperature to get the value of $1.175 \mathrm{~kg} / \mathrm{m}^{3}$. The pitch angle shown in the turbine page does not affect the power flow directly as there is a pitch controller, which keeps the rotor speed within operating limits.

The wind characteristics page in Fig. 5 is used to enter wind-related factors that ETAP can use to create a wind profile for a wind farm. As per the annual mean speed records in the weather station, a height of 40 meters above the ground is needed to reach an average speed of 6 $\mathrm{m} / \mathrm{s}$. Therefore, the tower height should not be less than 40 meters and the rotor diameter should be suitable with that height. The tower height chosen in this study is 65 meters, 60 meters of which is the rotor diameter. In addition, to investigate the possibility of using smaller wind turbines, simulation study is repeated for 39 meters rotor diameter to compare the output power with 60 meters rotor. The output voltage of the wind turbines is chosen as $11 \mathrm{kV}$ to reduce losses and avoid the need for a transformer.

The system in Fig. 3 was modified to represent the Diesel/Wind Hybrid system shown in Fig. 7. The only difference with Fig. 3 is the replacement of the retired diesel generators at Khaloof and Najdah by wind energy systems.

Table 1. Technical specifications of the wind turbine.

\begin{tabular}{lc}
\hline Description & Selected Wind Energy System \\
\hline Rated Power (each Turbine) & $0.5 \mathrm{MW}$ \\
Rated Wind Speed & $15 \mathrm{~m} / \mathrm{s}$ \\
Cut-in Wind Speed & $4 \mathrm{~m} / \mathrm{s}$ \\
Cut-out Wind Speed & $25 \mathrm{~m} / \mathrm{s}$ \\
Rotor Diameter & $60 \mathrm{~m}$ \\
Tower height & $65 \mathrm{~m}$ \\
Swept Area (ח $\left.\mathrm{r}^{2}\right)$ & $2828 \mathrm{~m}^{2}$ \\
Rated Voltage & $12 \mathrm{kV}$ \\
No. of Turbines & 5 \\
No. of Blades & 3 \\
\hline
\end{tabular}




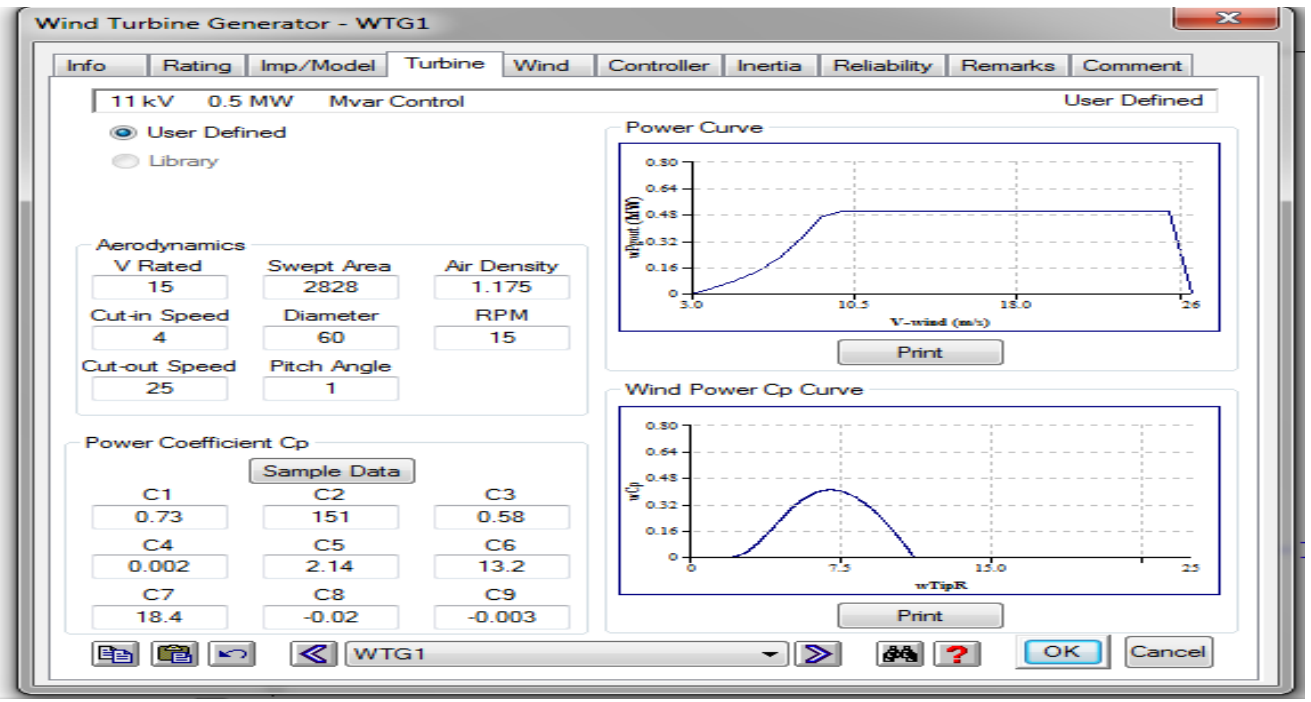

Figure 5. Aerodynamics page of wind turbine.

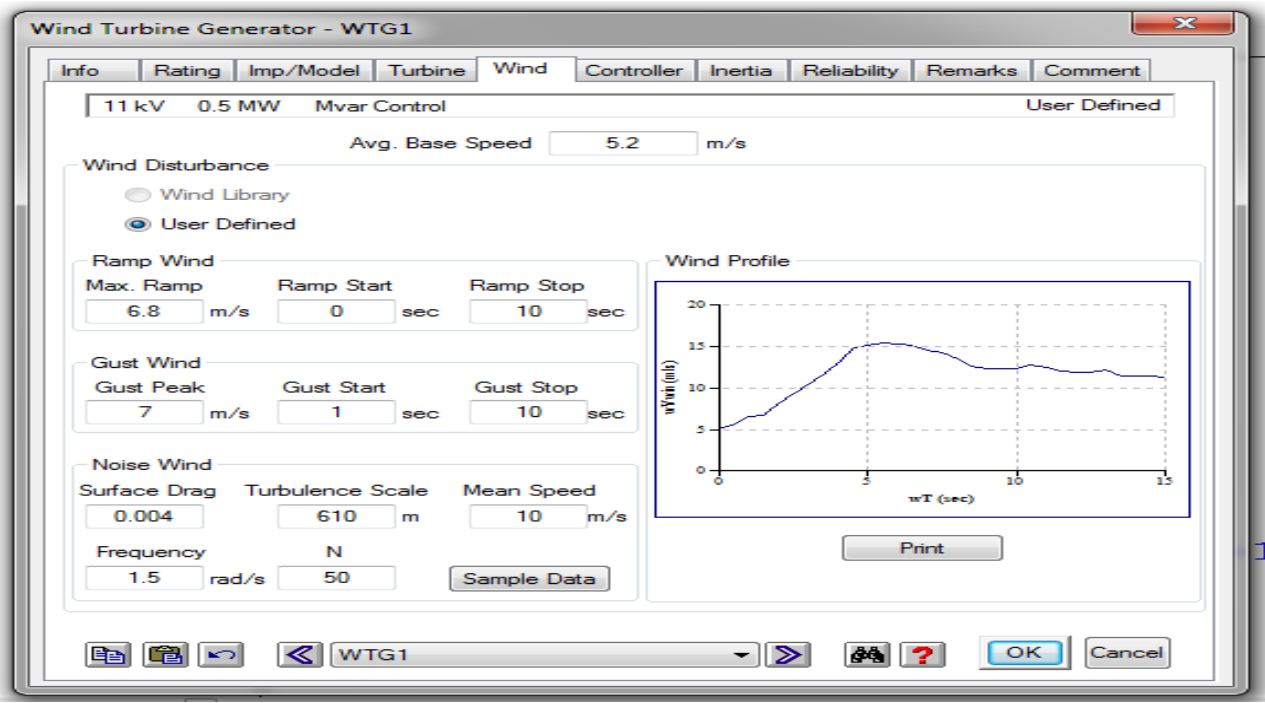

Figure 6. Wind characteristics page of wind turbine.

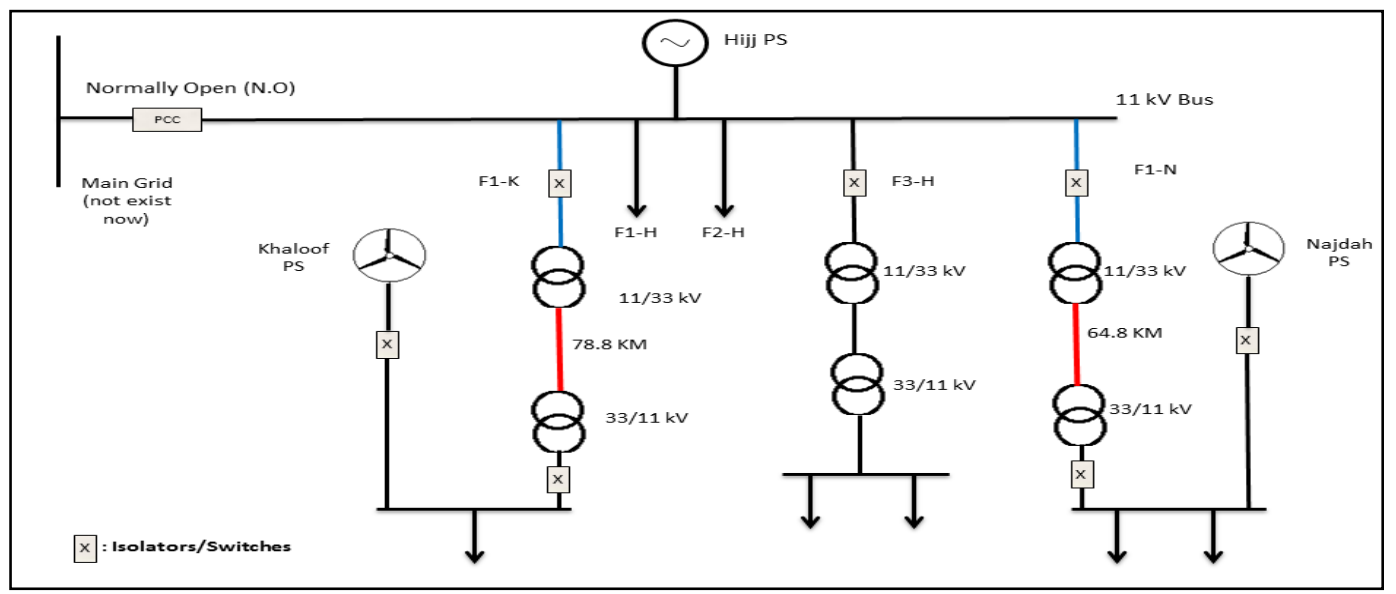

Figure 7. Full scheme for the proposed microgrid using wind and diesel. 


\section{Results}

\subsection{Part I: Interlinking Systems Using Diesel Generators Only}

In this case, the three systems are interlinked for constructing the microgrid, with Najdah and Khaloof stations switched off and the microgrid fed from the diesel generators in Hijj station, as shown in Fig. 3. On running power flow using ETAP, as shown in Fig. 8, a warning indicator was noticed for overload in generation by more than $4.2 \%$ from the specified maximum output, which is given as $12.766 \mathrm{MW}$ at 0.9 power factor. Therefore, the overload issue has to be solved by upgrading the generators inside Hijj power station by $6.4 \%$ from their existing capacity. This means that the ratings of the power station need to be upgraded from 12.776 MW (14.2 MVA) to 13.59 MW (15.1 MVA).

After upgrading the generators, the installation of step-up and step-down transformers in both systems has been taken into consideration. Power flow analysis showed that without transformers, both Khaloof system and Najdah system suffered from a voltage drop as high as $19 \%$. There are different approaches to improve the voltage profile and reduce the voltage drop; the easiest way is to improve the voltage profile is by the installation of step-up or step-down transformers (Vandoorn, De Kooning et al. 2013). For interlinking Hijj, Khaloof and Najdah systems, 2 MVA step-up and step-down transformers were used.

As shown in Table 2, no significant voltage drop or overload issue appeared in the system and the apparent power was within the specified limits. Permissible voltage drop in 11 , 33 and $0.415 \mathrm{kV}$ systems is $\pm 6 \%$ of the rated voltage according to Oman Distribution Code. The current rating of $11 \mathrm{kV}$ bus bar at Hijj power station is $630 \mathrm{~A}$ for each feeder.

\subsection{Part II: Interlinking Systems Using Hybrid Wind-Diesel Resources}

After adding wind energy systems to Khaloof and Najdah, the system performance improved considerably. The power flow results are shown in Table 3 and Fig. 9. The voltage profile improved in both systems and the overall losses in the system became 0.262 j0.543 MVA, which is obviously better than merely using diesel generators. In this case, Najdah and Khaloof diesel generator stations are switched off and the microgrid is fed from the diesel generators in Hijj station and local wind generators in Najdah and Khaloof. However, while running the power flow using ETAP, an alert was noticed for overload in generation by more than $4.2 \%$ from the specified maximum output. This is due to the fact that wind energy systems usually produce less power output than their capacity. However, the overload issue can be solved by upgrading the generators inside Hijj power station by $6.4 \%$ from their existing capacity. This means that power station rate will change from $12.776 \mathrm{MW}$ to $13.59 \mathrm{MW}$. The contribution of the sources is shown in Table 4, which shows that the Hijj power station has been upgraded to $13.59 \mathrm{MW}$, 0.92 power factor, and each wind generator supplies only $4.3 \%$ of the total required generation. This, of course, depends on wind speed and some other conditions.

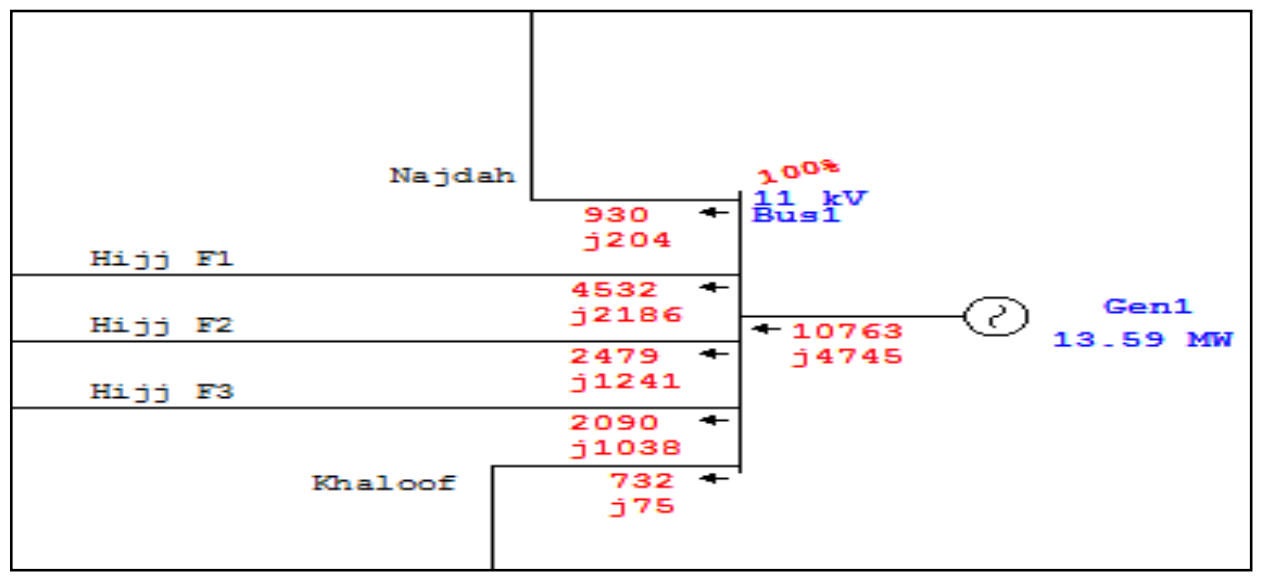

Figure 8. Power Flow for the outgoing feeders from Hijj station in scenario 1. 
Table 3. Power flow using wind turbines in Khaloof in Najdah stations.

\begin{tabular}{llllll}
\hline Feeder & F1-H & F2-H & F3-H & F1-K & F1-N \\
\hline S(KVA) at (beginning of Feeder) & $4.5+\mathrm{j} 2.2$ & $2.5+\mathrm{j} 1.2$ & $2.1+\mathrm{j} 1$ & $0.7+\mathrm{j} 0.08$ & $0.9+\mathrm{j} 0.2$ \\
\hline
\end{tabular}

Table 4. Contributions of wind turbines in Khaloof in Najdah stations.

\begin{tabular}{lllllll}
\hline Source & Type & $\begin{array}{l}\text { Rating } \\
\text { MW }\end{array}$ & $\begin{array}{l}\text { Active } \\
\text { MW }\end{array}$ & $\begin{array}{l}\text { \% Local } \\
\text { Supply } \\
\text { Contribution }\end{array}$ & \% PF & $\begin{array}{l}\text { \% Total Supply } \\
\text { Contribution }\end{array}$ \\
\hline Gen1 & Syn. & 13.59 & 9.926 & 100 & 91.97 & 91.6 \\
WTG1 & Wind. & 2.5 & 0.456 & 60.5 & 90.07 & 4.2 \\
WTG2 & Wind. & 2.5 & 0.456 & 59.6 & 90.07 & 4.2 \\
\hline
\end{tabular}

Table 5. Increasing wind turbines in Khaloof in Najdah stations.

\begin{tabular}{llllll}
\hline Source & Type & $\begin{array}{l}\text { Rating } \\
\text { MW }\end{array}$ & $\begin{array}{l}\text { Active } \\
\text { MW }\end{array}$ & \% PF & Voltage (\% Mag.) \\
\hline Gen1 & Syn. & 13.59 & 9.114 & 90.1 & 100 \\
WTG1 & Wind. & 6.0 & 1.095 & 90.4 & 104.49 \\
WTG2 & Wind. & 4.0 & 0.730 & 91.1 & 101.07 \\
\hline
\end{tabular}

Table 6. Daily wind turbines contribution in generation.

\begin{tabular}{lllll}
\hline \multicolumn{2}{c}{ Morning } & \multicolumn{2}{c}{ Evening } \\
\hline \multirow{2}{*}{ Station } & $\begin{array}{l}\text { Gen. power at min. } \\
\text { speed }(3.2 \mathrm{~m} / \mathrm{s})\end{array}$ & $\begin{array}{l}\text { Gen. power at max. } \\
\text { speed }(4.5 \mathrm{~m} / \mathrm{s})\end{array}$ & $\begin{array}{l}\text { Gen. power at min. } \\
\text { speed }(5.8 \mathrm{~m} / \mathrm{s})\end{array}$ & $\begin{array}{l}\text { Gen. power at max. } \\
\text { speed }(8.1 \mathrm{~m} / \mathrm{s})\end{array}$ \\
\cline { 2 - 5 } & $\mathrm{S}(\mathrm{Mva})$ & $\mathrm{S}(\mathrm{Mva})$ & $\mathrm{S}(\mathrm{Mva})$ & $\mathrm{S}(\mathrm{Mva})$ \\
Khaloof & $\mathrm{j} 0.2$ & $0.29+\mathrm{j} 0.2$ & $0.6+\mathrm{j} 0.2$ & $1.72+\mathrm{j} 0.2$ \\
Najdah & $\mathrm{j} 0.2$ & $0.29+\mathrm{j} 0.2$ & $0.6+\mathrm{j} 0.2$ & $1.72+\mathrm{j} 0.2$ \\
\hline
\end{tabular}

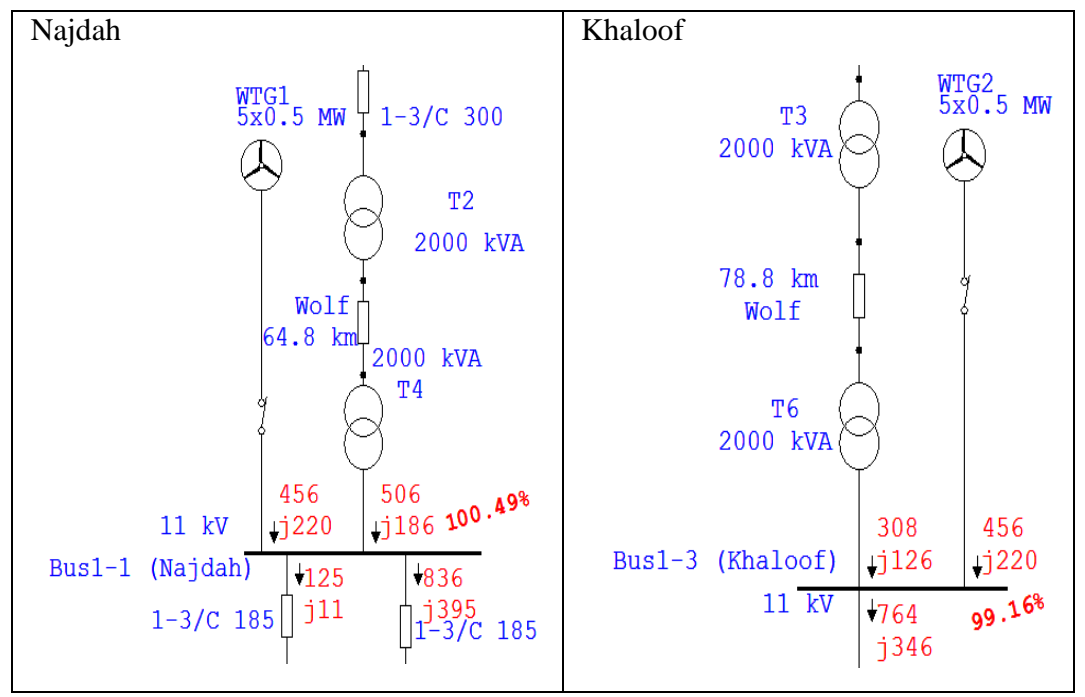

Figure 9. Power flow results of wind turbines in Khaloof and Najdah. 
Wind energy systems are only proposed for Najdah and Khaloof, and not for Hijj. This can be considered in the future. The revised Table 4 shows that in Najdah $506 \mathrm{~kW}$ is supplied by wind turbines, i.e. $60.5 \%$ of the required power in Najdah. Similarly, $59.6 \%$ of power used in Khaloof is supplied by wind turbines. However, only $8.4 \%$ of the total required power in Hijj, Khaloof and Najdah systems is supplied by wind energy systems. This is due to the fact that no renewable resource is proposed for Hijj power station.

In all the above cases, annual average wind speed is used. However, the daily wind speed gives a clearer picture of wind turbines' contribution of wind turbines in supplying power. It is expected that in some seasons and times, wind energy systems contribute much more to the generation of the electrical power needed to supply the loads.

Studying the power flow using daily wind speed, as shown in Table 6, shows that the maximum output from turbines is during the evening when they comply with maximum power demand.

Rotor diameter is one of the parameters that affects the output power. There is proportionality between the output power and rotor diameter. Table 7 presents the output from the wind turbines using 39 meters rotors. In comparing Table 6 with Table 7, it is observed that the output power of wind turbines with 39 meters rotors for the same wind speed is reduced to about half of the output of 60 meters rotors. This suggests the selection of 60 meters rotor instead of 39 meters rotor if single wind turbine is used. Unquestionably, another suggested option, in this case, is to use more wind turbines. So, in that case, it is expected that even with 39 meters rotors, a good portion of the required power can be supplied by wind energy systems.

\section{Proposing Future Work}

The demand of power in rural areas is increasing continuously. It is proposed that the rural power system of three small towns can be interlinked to work as a multi-microgrid. This system needs to be made smart by using renewable resources with advanced control systems (Hamzeh, Emamian et al. 2016). At the same time, switching off non-efficient diesel stations has to be the priority of the electricity company authorized in rural areas of Oman. With respect to this, there are some arising issues (see below) which have not been addressed in this paper and will be studied as future research.

- Controlling the microgrid (Sheng, Wang et al. 2010; Shafiee, Guerrero et al. 2014) in a practical way applied to the case study by constructing SCADA systems and building local and central controllers with advanced technologies for controlling the power (Senthilkumar and Narmadhadevi 2013) and dispatching it between the sources of a microgrid (Rodriguez-Amenedo, Arnalte et al. 2002; Varaiya, Wu et al. 2011).

- Since there is a plan to make the grid available close to the rural network under study, future research may also focus on the microgrid in the grid-connected mode instead of the study carried out for islanded mode. Currently, Oman's main grid is around $250 \mathrm{~km}$ away from the Hijj system. There is a possibility of extending $132 \mathrm{kV}$ up to Hijj, which will make the shutting down of the diesel power station possible.

- Studying the financial and environment aspects of the constructed microgrid.

- Developing a methodology to design and implement hybrid Wind-Diesel microgrid.

- Constructing the proposed wind turbines in Hijj and test them in practice.

- A regulatory framework is needed for encouraging consumers to participate in power generation using renewable resources.

Table 7. Sources output using 39 meter rotor diameter.

\begin{tabular}{llllll}
\hline Source & Rating (MW) & Active (MW) & Reactive (Mvar) & \% PF & \% Generation \\
\hline $\begin{array}{l}\text { WTG1 Najdah } \\
\text { WTG2 }\end{array}$ & 2.5 & 0.193 & 0.22 & 65.9 & 2.1 \\
Khaloof & 2.5 & 0.193 & 0.22 & 65.9 & 2.1 \\
\hline
\end{tabular}




\section{Conclusion}

In this paper, it is proposed to use wind energy conversion systems (WECS) as a part of a multimicrogrid for the existing rural networks in Hijj, Khaloof and Najdah in the Sultanate of Oman. The WECS technology is used to reduce the usage of diesel generators, which have high operating costs and also add to environmental pollution. It is proposed that some small power stations that use diesel generators be retired and instead power flow be managed by interlinking existing isolated power systems plus adding WECS where feasible. The system performance is studied mainly by power flow analysis of the system before and after interlinking between the aforementioned systems. The study is carried out on an actual power system in rural Oman with all parameters obtained from a real system in operation. It was shown that microgrid could be enhanced by using wind turbines in place of switched-off power stations. These wind turbines ensure the system reliability while producing less pollution compared to diesel generators. However, more advanced control is needed for converting these intermittent sources of energy to dispatch-able generators.

This paper contributes to the technical feasibility study of using renewable energy sources and reducing the usage of diesel generators in rural Oman. The financial and environment aspects of the constructed microgrid need to be studied too. These studies are essential before making a final decision on constructing the proposed microgrid. To study the financial aspects pertaining to this microgrid, market price has to be provided in addition with actual bill of quantity needed for construction or upgrade of power station, feeders, substations, etc. This is under study by the authors.

\section{Conflict of Interest}

The authors declare no conflicts of interest.

\section{Funding}

This work is funded by The Research Council (TRC) grant ORG-SQU-E1-11-009 (RC/ENG/ECED/12/02).

\section{Acknowledgment}

The authors would like to thank SQU, The Research Council, and Oman Rural Area Electricity Company (RAEC) for their support to this research work.

\section{References}

Al Hatmi Y, Tan C (2013), Issues and challenges with renewable energy in Oman. Gas (BCM) 4(9): 212-218.

Ceh EHC (2013), Introduction to microgrids.

Chuang SJ, Hong CM, Chen CH (2016), Design of intelligent control for stabilization of microgrid system. International Journal of Electrical Power \& Energy Systems 82: 569578.

Costa PM, Matos MA, Lopes JP (2008), Regulation of microgeneration and microgrids. Energy Policy 36(10): 3893-3904.

Esmaeli A (2016), Stability analysis and control of microgrids by sliding mode control. International Journal of Electrical Power and Energy Systems 78: 22-28.

Hamzeh M, Emamian S, Karimi $H$, Mahseredjian J (2016), Robust control of an islanded microgrid under unbalanced and nonlinear load conditions. IEEE Journal of Emerging and Selected Topic in Power Electronics 4(2): 512-520.

Hatziargyriou N, Asano H, Iravani R, Marnay C (2007), Microgrids. Power and Energy Magazine IEEE 5(4): 78-94.

Hemmatpour $\mathrm{MH}$, Mohammadian $\mathrm{M}$, Gharaveisi AA (2016), Optimum islanded microgrid reconfiguration based on maximization of system loadability and minimization of power losses. International Journal of Electrical Power and Energy Systems 78: 343-355.

Hosseinzadeh N, Mayer JE, Wolfs PJ (2011), Rural single wire earth return distribution networks-associated problems and costeffective solutions. International Journal of Electrical Power and Energy Systems 33(2): 159-170.

Jiayi H, Chuanwen J, Rong X (2008), A review on distributed energy resources and microgrid. Renewable and Sustainable Energy Reviews 12(9): 2472-2483. 
Khederzadeh M, Maleki H, Asgharian V (2016), Frequency control improvement of two adjacent microgrids in autonomous mode using back to back voltage-sourced converters. International Journal of Electrical Power and Energy Systems 74: 126-133.

Khodayar ME, Barati M, Shahidehpour M (2012), Integration of high reliability distribution system in microgrid operation. IEEE Transactions on Smart Grid 3(4): 19972006.

Lasseter RH (2011), Smart distribution: Coupled microgrids. Proceedings of the IEEE 99(6): 1074-1082.

Li C, Liu X, Cao Y, Zhang P, Shi H, Ren L, Kuang Y (2016), A time-scale adaptive dispatch method for renewable energy power supply systems on islands. IEEE Transactions on Smart Grid 7(2): 1069-1078.

Marnay C, Venkataramanan G (2006), Microgrids in the evolving electricity generation and delivery infrastructure. Paper presented at the 2006 IEEE Power Engineering Society General Meeting.

Meng L, Luna A, Diaz ER, Sun B, Dragicevic T, Savaghebi M, Andrade F (2016), Flexible system integration and advanced hierarchical control architectures in the microgrid research laboratory of Aalborg University. IEEE Transactions on Industry Applications 52(2): 1736-1749.

Mohan V, Singh JG, Ongsakul W, Suresh MR (2016), Performance enhancement of online energy scheduling in a radial utility distribution microgrid. International Journal of Electrical Power and Energy Systems 79: 98107.

Moradi MH, Eskandari M, Hosseinian SM (2016), Cooperative control strategy of energy storage systems and micro sources for stabilizing microgrids in different operation modes. International Journal of Electrical Power and Energy Systems 78: 390400.

Nikmehr N, Ravadanegh SN (2016), Reliability evaluation of multi-microgrids considering optimal operation of small scale energy zones under load-generation uncertainties. International Journal of Electrical Power and Energy Systems 78: 80-87.

Oman-AER (2008), Study on renewable energy resources. Regulation AFE, (2008). Study on renewable energy resources, from http://www.aer-oman.org

Rodriguez-Amenedo JL, Arnalte S, Burgos JC (2002), Automatic generation control of a wind farm with variable speed wind turbines. IEEE Transactions on Energy Conversion 17(2): 279-284.

Schwaegerl C, Tao L (2014), The microgrids concept. Microgrids: Architectures and Control $1-24$.

Senthilkumar A, Narmadhadevi V (2013), Real and reactive power control of doubly-fed induction generator during voltage sag. International Journal of Engineering Research and Technology.

Shafiee Q, Guerrero JM, Vasquez JC (2014), Distributed secondary control for islanded microgrids-A novel approach. IEEE Transactions on Power Electronics 29(2): 10181031.

Shahnia F (2011), Analysis and correction of voltage profile in low voltage distribution networks containing photovoltaic cells and electric vehicles. Queensland University of Technology.

Sheng SR, Wang XY, Xu HZ, Zhu GQ, Zhou YF (2010), Anatomy of large animal spines and its comparison to the human spine: a systematic review. Euro Spine Journal 19(1): 46-56.

Sun Q, Zhou J, Guerrer JM, Zhang H (2015), Hybrid three-phase/single-phase microgrid architecture with power management capabilities. IEEE Transactions on Power Electronics 30(10): 5964-5977.

Vandoorn TL, De Kooning JD, Meersman B, Guerrero JM, Vandevelde L (2013), Voltagebased control of a smart transformer in a microgrid. IEEE Transactions on Industrial Electronics 60(4): 1291-1305.

Varaiya PP, Wu FF, Bialek JW (2011), Smart operation of smart grid: Risk-limiting dispatch. Proceedings of the IEEE 99(1): 40-57.

Xu Z, Nthontho M, Chowdhury S (2016), Rural electrification implementation strategies through microgrid approach in South African context. International Journal of Electrical Power and Energy Systems 82: 452465. 